\title{
DEM simulations of soil creep due to particle crushing
}

\author{
C. Y. KWOK* and M. D. BOLTON†
}

\begin{abstract}
One mechanism that may contribute to creep in sand is that heavily loaded grains may progressively crush, following the growth of microcracks due to hydrolysis at crack tips. Weibull's statistical model of brittle failure can accommodate these time effects. Discrete-element modelling (DEM) simulations of the temporal deterioration of loaded grains were conducted using Robertson's bonded agglomerates of microspheres to represent the grains. A time-dependent failure equation that describes crack growth corresponding to increasing grain stress was developed. The equation was incorporated into a single DEM agglomerate to simulate the deterioration of loaded grains. It is found that a particular relationship can be derived between the rate of loss of bond strength at a contact and the tension carried at that contact, such that the Weibull modulus of this rate-dependent model matches that of short-term loading tests on individual sand grains. A strength-probability-time diagram was generated that enables estimation of delayed fracture. The predicted grain strength decreases in a nearly linear fashion with the logarithm of time, which is in good agreement with previous results for ceramics. This DEM technique was then applied to the simulation of creep in a triaxial test with 378 breakable grains. The DEM results show that crack growth can lead to softening of samples with volumetric contraction due to grain breakage accompanying dilation due to shearing. Creep-induced failure might be anticipated when the axial strain reaches about $5 \%$.
\end{abstract}

KEYWORDS: creep; failure; numerical modelling; time dependence

\section{INTRODUCTION}

The time-dependent behaviour of soil has been a phenomenon of much concern in many geotechnical engineering applications, including the settlement of pile foundations, the deformations of earth structures, the movements of natural and excavated slopes, and the squeezing of soft ground around tunnels. At present, no general constitutive model exists that can adequately predict the time-dependent deformation of soils under arbitrary three-dimensional states of stress. Although soil consolidation due to transient flow is the most commonly encountered rate process in geotechnical engineering, soil creep is also found to occur under conditions of constant effective stress. There is therefore a pressing need to identify the mechanisms that may be responsible for creep, so that more comprehensive models can be written, and more reliable predictions made.

Different mechanisms have been proposed to account for the observed change in a soil's creep rate with time. Kuhn \& Mitchell (1993) summarised the possible mechanisms. They can be classified into two groups: deformation-dependent mechanisms that are based on changes in soil structure that accompany deformation, and those based on intrinsically time-dependent processes such as chemical reactions. McDowell \& Bolton (1998) suggested that, under low stress, deformation is due to particle rearrangement, but fragment splitting becomes the dominating mechanism if load is increased further. Kwok \& Bolton (2010) modelled the creep mechanism based on grain sliding. In this paper, the main focus on the creep mechanism is particle breakage and reorientation, which is widely suggested by researchers.

Lee \& Farhoomand (1967) were the first to indicate time-

Manuscript received 12 July 2011; revised manuscript accepted 17 July 2013. Published online ahead of print 16 September 2013.

Discussion on this paper closes on 1 May 2014, for further details see p. ii.

* Department of Civil Engineering, University of Hong Kong, Hong Kong.

$\dagger$ Department of Engineering, University of Cambridge, UK. dependent behaviour of granular soil due to particle crushing at high stress using isotropic and anisotropic triaxial compression tests. Vesić \& Clough (1968) took the pressure range during isotropic compression tests on sand as high as $62 \mathrm{MPa}$, and observed an increase in grain breakage with irreversible volumetric compression, followed by significant secondary consolidation (i.e. creep) continuing for at least $1 \mathrm{~h}$. Takei et al. (1998) showed that plate settlement increases linearly with the logarithm of loading duration, and that the larger the sustained loads, the greater was the rate of creep settlement. Thus it is considered that the time-dependent settlement of the plate was caused by a particle-crushing phenomenon. Takei et al. (2001) conducted one-dimensional compression tests on four crushable materials (chalk bars, talc bars, glass beads and quartz particles), and showed that the time-dependent behaviour stemmed mainly from a repetitive cycle of crushing, rearrangement of particles, and redistribution of contact stresses. McDowell \& Khan (2003) performed one-dimensional creep tests on aggregates of brittle pasta and compared them with the behaviour of sand at much higher stress levels. It was found that the creep behaviours of sand and pasta are very similar, both exhibiting creep strain proportional to the logarithm of time. Leung et al. (1996) and Yet et al. (1996) carried out centrifuge tests of a pile under sustained loads, and observed that the creep settlement of the pile increased almost linearly with the logarithm of time. Yet et al. (1996) presumed that one possible reason for the creep phenomenon could be particle breakage. With greater load, the interlocking particle stress is larger, and hence more particle breakdown occurs. Others, such as Barksdale \& Blight (1997) and Mukai et al. (1999), have reported observations of the progressive settlement of full-scale structures several years after completion.

The progressive settlement of rock fill was the focus of concern for Oldecop \& Alonso (2007), who proposed a conceptual model based on the delayed fracture of heavily stressed rockfill elements. They recognised that broken fragments would pack more efficiently in pre-existing voids, permitting densification and settlement. The mechanism of 
delayed fracture in ceramics (Wiederhorn et al., 1980; Freiman, 1984) had earlier been shown to be analogous to stress-corrosion cracking in certain ductile metals that can degrade when held in tension, owing to microcrack growth in the presence of chloride-rich water. Microcracks in ceramics can similarly extend at a rate determined by the tensile stress at the crack tip, and the availability of water or water vapour to feed a chemical reaction known as hydrolysis at the tips of surface cracks. This understanding of the behaviour of ceramics, illustrated in Fig. 1, has become generally available through modern textbooks in materials engineering (Ashby \& Jones, 1998). Oldecop \& Alonso (2007) applied the same crack propagation concept to consider the delayed breakage of rock particles leading to a required rearrangement of granular structure in order to reach a new equilibrium configuration, with progressive macroscopic strain being perceived as creep. A similar explanation based on progressive grain damage and deterioration has been advocated to explain the data of timerelated strains in sands (Karimpour \& Lade, 2010).

This hypothetical mechanism is investigated in this paper through discrete-element modelling (DEM). The commercial software Particle Flow Code in three dimensions $\left(\mathrm{PFC}^{\mathrm{D}} \mathrm{D}^{\mathrm{TM}}\right.$ ) (Itasca, 2008) was used to study assemblies of individual particles. In order to simulate particle breakage, soil grains can be represented in DEM by numerical agglomerates. The agglomerates consist of individual spheres bonded together in a crystalline array containing random flaws, a technique first developed by Robertson (2000). Robertson \& Bolton (2001) developed an agglomerate model that is able to model grain crushing as a crucial granular characteristic of soils. In the current work, a mathematical model is developed that stipulates the decay of bond strength with time in order to simulate the deterioration of grain strength under sustained loading. This bond-deterioration model is first incorporated into a single grain to verify that the proposed model of agglomerate fracture follows Weibull statistics corresponding to increasing failure times. A strength-probability-time (SPT) diagram is generated involving statistical variations in strength and a time effect under stress that can ultimately be used to predict time-dependent failure in a quantitative way. DEM simulations are then reported of the behaviour of an

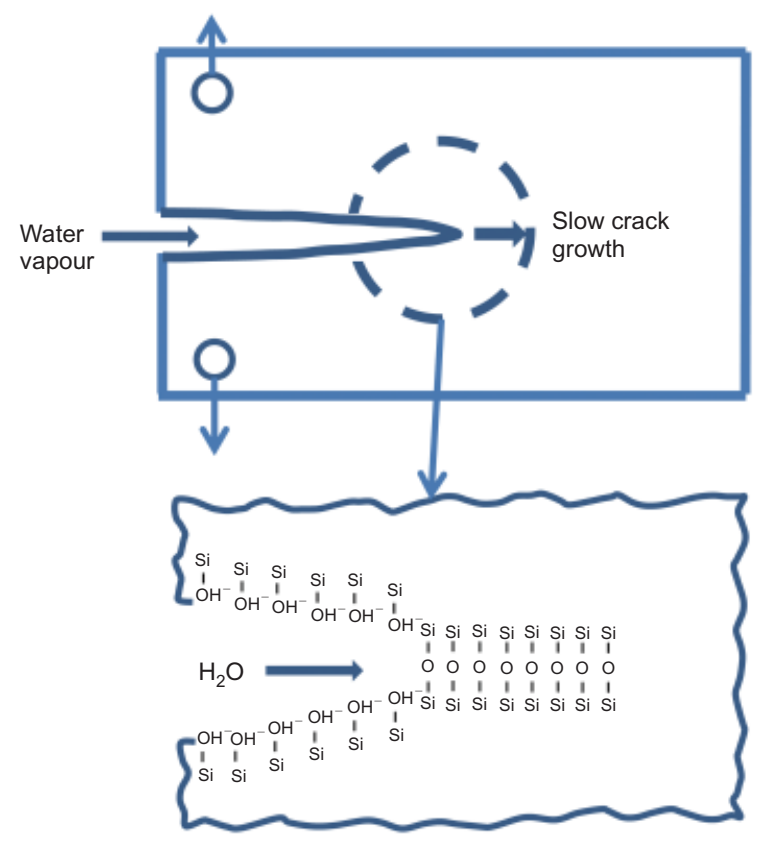

Fig. 1. Slow crack growth caused by surface hydration of oxide ceramics (Ashby \& Jones, 1998) assembly of agglomerates, in an attempt to model creep in a high-stress triaxial test exhibiting particle breakage.

\section{CRACK GROWTH IN A SINGLE GRAIN}

Weibull statistics: statistical variation in strength

The resistance of a solid to brittle fracture is determined by failure at the weakest point of the solid. Weibull statistics is based on the weakest link proposition, which, when applied to fibres, basically states that longer fibres have larger failure probabilities. As a result of defects in ceramic materials, the stress at which a specimen fractures can vary widely. The Weibull distribution can be used to describe the variation of tensile strength of apparently identical samples of a brittle material. Because a given ceramic will have a range of flaw sizes, there will be a corresponding variation in strength. Weibull (1951) proposed that for a block of material of volume $V$ under a uniform tensile stress $\sigma$, the probability of survival of the block $P_{\mathrm{s}}(V)$ is given by equation (1), which can also be written as equation (2) if $V=V_{0}$.

$$
P_{\mathrm{s}}(V)=\exp \left[-\left(\frac{V}{V_{0}}\right)\left(\frac{\sigma}{\sigma_{0}}\right)^{m}\right]
$$

$V_{0}$ is the volume of material such that

$$
P_{\mathrm{s}}\left(V_{0}\right)=\exp \left[-\left(\frac{\sigma}{\sigma_{0}}\right)^{m}\right]
$$

Here $V_{0}$ is the characteristic volume, $\sigma_{0}$ is the characteristic stress at which $1 / \mathrm{e}$ or $37 \%$ of tested specimens survive, and $m$ is the Weibull modulus, which quantifies the scatter of the strength values (i.e. high values of $m$ indicate low scatter, as shown in Fig. 2). Materials such as chalk, brick, stone and pottery have $m \approx 5$; engineering ceramics such as dense alumina $\left(\mathrm{Al}_{2} \mathrm{O}_{3}\right)$ and silicon carbide (SiC) have $m \approx 10$, and the variation in strength is much less (Ashby \& Jones, 1998).

By taking double natural logarithms, equation (2) can be rewritten as

$$
\ln \left[\ln \left(\frac{1}{P_{\mathrm{s}}}\right)\right]=m \ln \left(\frac{\sigma}{\sigma_{0}}\right)
$$

When $\sigma / \sigma_{0}=0$, all particles survive and $P_{\mathrm{s}}=1$. As $\sigma / \sigma_{0}$ increases, more and more particles fail, and $P_{\mathrm{S}}$ decreases. Equation (3) has been reported to be successful (Cheng et al., 2003) in organising both the data of grain crushing and the performance of DEM simulations, as illustrated in Fig. 3(a).

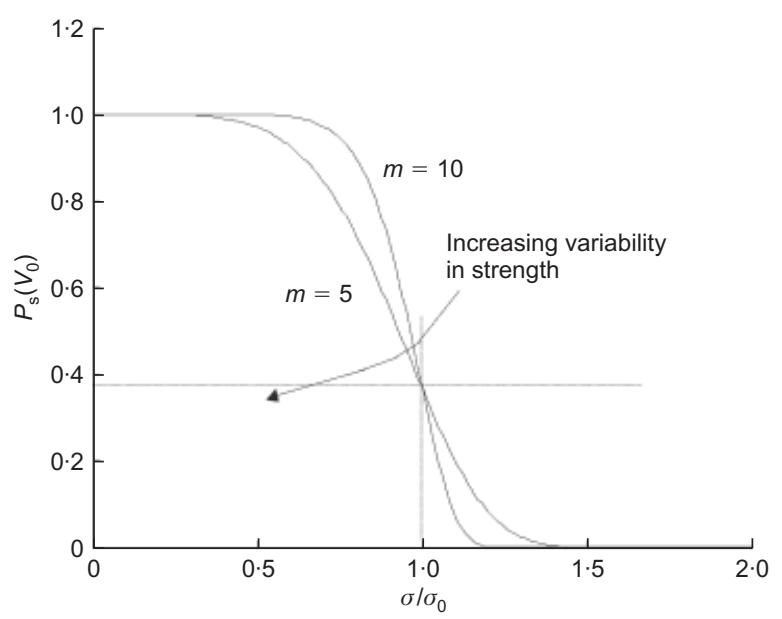

Fig. 2. Weibull distributions of strengths (McDowell \& Amon, 2000) 


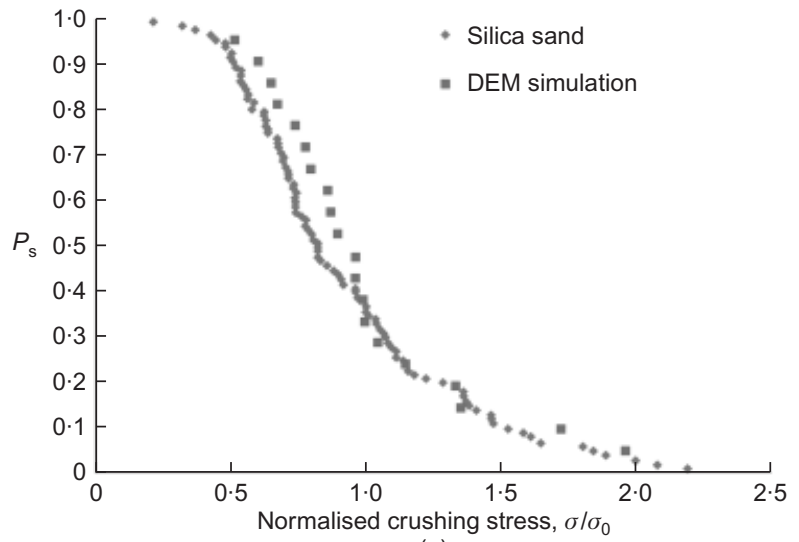

(a)

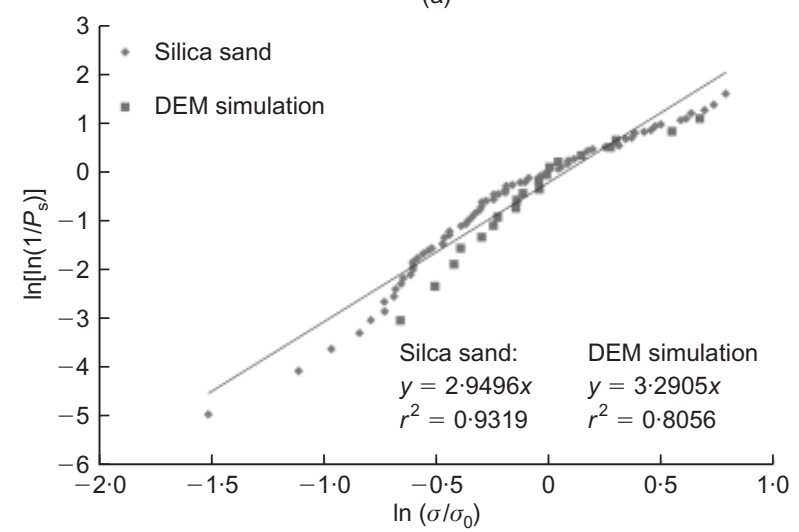

(b)

Fig. 3. Survival distribution curve of single agglomerate crushing (Cheng et al., 2003): (a) normalised distribution; (b) Weibull modulus

McDowell \& Amon (2000) have provided evidence to validate the use of Weibull statistics as a tool in the analysis of particle crushing. Such a statistical approach can then be used to analyse particle survival in aggregates comprising many soil particles. Robertson (2000) conducted individual crushing simulations on 20 DEM agglomerates to estimate a Weibull modulus of approximately $3 \cdot 3$, which is similar to that of silica sand, as shown in Fig. 3(b).

\section{Time-dependent failure}

Ceramics exhibit delayed fracture. Suppose that a particular bond representing a small region of material has an initial strength $B_{0}$, but that this reduces with time $t$, and at a rate that increases with the tension $T$ that it carries. An equation that describes this deterioration as a power law, often encountered in material science, is

$$
\frac{\mathrm{d} B}{B}=-\alpha\left(\frac{T}{B_{0}}\right)^{\beta} \frac{\mathrm{d} t}{t}
$$

where $B$ is now the bond strength at time $t, \alpha$ is a parameter that controls the rate of degradation and $\beta$ is a parameter that influences the sensitivity of the rate of deterioration to the current tensile force. Integrating equation (4) between limits

$$
\ln \frac{B}{B_{0}}=-\alpha\left(\frac{T}{B_{0}}\right)^{\beta} \ln \frac{t}{t_{0}}
$$

where $t_{0}$ is the time taken in a tension test to measure the tensile strength $T=B_{0}$. The work times $t_{0}$ are durations of tests, and $t_{0}$ is used to normalise statistical data. Equation (5) will be used here to describe the effect of hypothetical crack growth within a grain of soil, as illustrated below.
Crack growth in ceramics and rocks is known to be influenced by both the tensile force and the shear force applied to a testpiece. Hoek \& Brown (1980) derived a relationship between the normal and shear stresses at brittle failure, which has been expressed here in terms of the equivalent tensile strength $B$ of a zone of unit area carrying both a tensile force $T_{\mathrm{f}}$ and a shear force $S_{\mathrm{f}}$.

$$
B=-\frac{1}{2}\left[\left(T_{\mathrm{f}}^{2}+S_{\mathrm{f}}^{2}\right)^{1 / 2}+T_{\mathrm{f}}\right]
$$

This permits the derivation of an equivalent tensile force $T_{\mathrm{eq}}$ for material not yet at fracture (Fig. 4)

$$
T_{\text {eq }}=-\frac{1}{2}\left[\left(T^{2}+S^{2}\right)^{1 / 2}+T\right]
$$

where $T$ is the current tensile force, and $S$ is the current shear force. Accordingly, $T_{\mathrm{eq}}$ will be used in place of $T$ when equation (5) is applied to a DEM bond carrying both $T$ and $S$.

Figure 5(a) shows the ratio of the equivalent tensile force to the initial bond strength against the logarithm of time to failure. When $T_{\mathrm{eq}}=B_{0}$, the agglomerate fails at time $t_{0}$, as defined earlier. If the magnitude of tensile force is smaller, it takes longer for a bond to break. Fig. 5(b) shows how bond strength decays with additional time units $\left(t-t_{0}\right)$, and that it decays more slowly when $\beta$ increases. In this case, $B_{0}$ is $4 \mathrm{~N}$ and $T_{\text {eq }}$ is $0.5 \mathrm{~N}$.

\section{Strength-probability-time (SPT) relationship}

The statistical effects of spatially random flaws can be combined with the subcritical crack growth time-dependent failure analysis to create an SPT diagram that describes the Weibull strength/probability-of-survival path corresponding to increasing failure times. Davidge et al. (1973) generated an SPT diagram by measuring the delayed fracture of alumina, as shown in Fig. 6. Lines are equally spaced for equal logarithmic increases in failure time. An individual specimen stressed at $\sigma_{1}$ and failing in time $t_{1}$ is therefore equivalent to a specimen failing at stress $\sigma_{2}$ in a reference time $t_{2}$. This relationship can be expressed as

$$
\left(\frac{\sigma_{1}}{\sigma_{2}}\right)^{n}=\frac{t_{2}}{t_{1}}
$$

where $n$ is the slow crack growth exponent. Data for $n$ are very limited, but it is $10-20$ for oxides at room temperature; for carbides and nitrides, it can be as large as 100 (Ashby \& Jones, 1998)

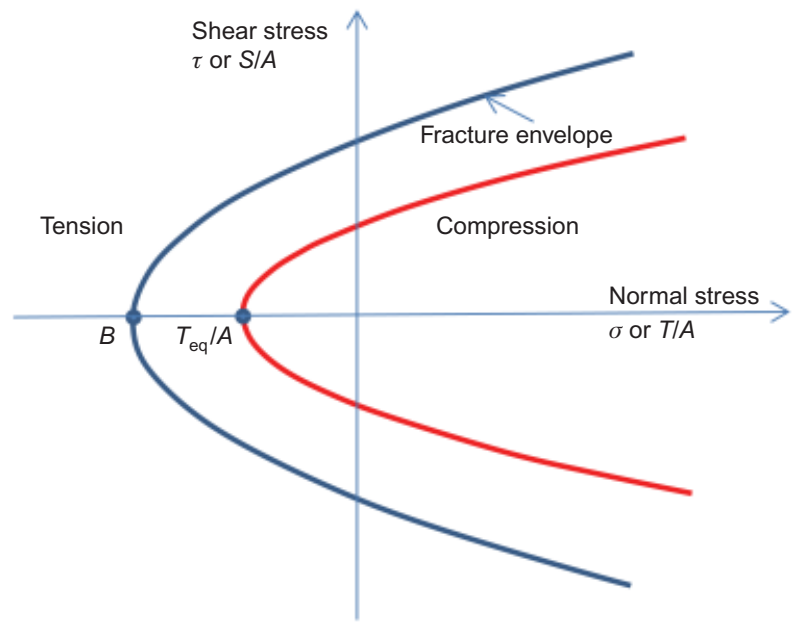

Fig. 4. Fracture envelope, showing relationships between stress components 

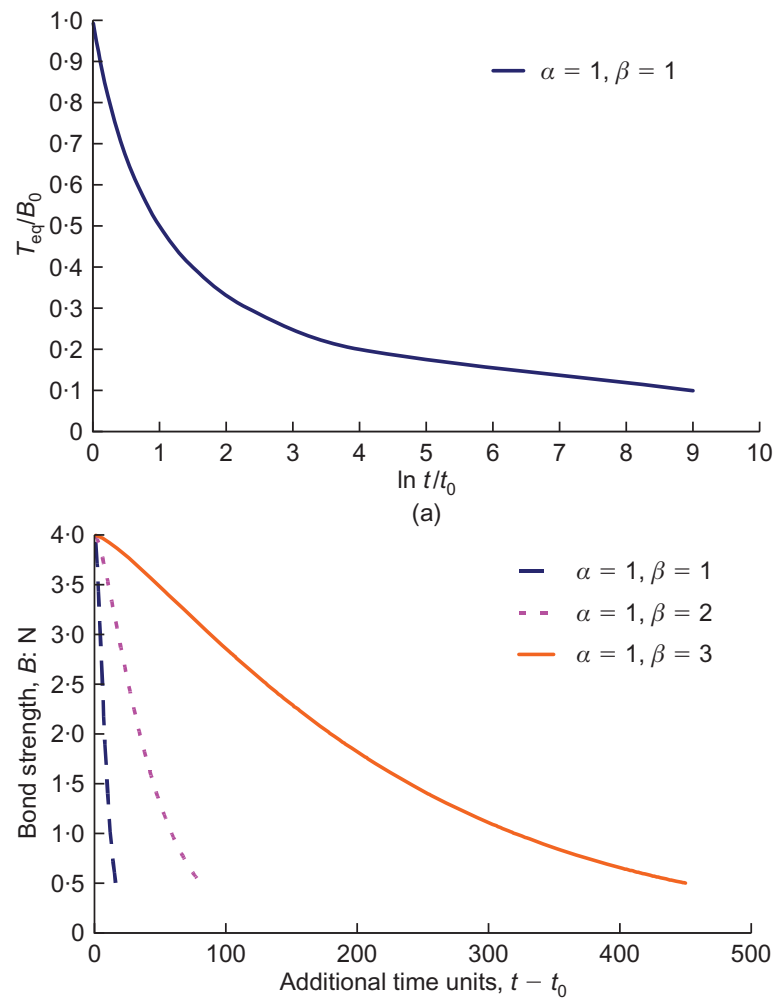

(b)

Fig. 5. Interpretation of equation (5): (a) plot of $T_{\mathrm{eq}} / B_{0}$ against In $t / t_{0}$; (b) plot of bond strength against additional time units $\left(t-t_{0}\right)$

It is proposed that, by merging the concepts of statistical variations with time-dependent failure, the probability of survival of the specimen, $P_{\mathrm{s}}$, becomes

$$
P_{\mathrm{s}}=-\exp \left[-\left(\frac{V}{V_{0}}\right)\left(\frac{\sigma}{\sigma_{0}}\right)^{m}\left(\frac{t}{t_{0}}\right)^{k}\right]
$$

If, for two specimens with the same $P_{\mathrm{s}}$, specimen 1 fails at $\left(\sigma_{1}, t_{1}\right)$ and specimen 2 fails at $\left(\sigma_{2}, t_{2}\right)$, equation (9) implies that

$$
\begin{gathered}
\sigma_{1}^{m} t_{1}^{k}=\sigma_{2}^{m} t_{2}^{k} \\
\left(\frac{\sigma_{1}}{\sigma_{2}}\right)^{m}=\left(\frac{t_{2}}{t_{1}}\right)^{k}
\end{gathered}
$$

By comparing equation (8) and equation (10), the following equation is derived

$$
m=n k
$$

However, assuming a unique elastic modulus $E$ until brittle failure, no matter how delayed the failure, it is also possible to write

$$
E=\frac{\sigma_{1}}{\varepsilon_{1}}=\frac{\sigma_{2}}{\varepsilon_{2}}
$$

So

$$
\frac{\sigma_{1}}{\sigma_{2}}=\frac{\varepsilon_{1}}{\varepsilon_{2}}
$$

and for steady strain rates,

$$
\frac{\sigma_{1} t_{2}}{\sigma_{2} t_{1}}=\frac{\dot{\varepsilon}_{1}}{\dot{\varepsilon}_{2}}
$$

Substituting equation (8) into equation (12), the following equation is obtained

$$
\left(\frac{\sigma_{1}}{\sigma_{2}}\right)^{n+1}=\frac{\dot{\varepsilon}_{1}}{\dot{\varepsilon}_{2}}
$$

which describes the relationship between strength $\sigma$ and strain rate $\dot{\varepsilon}$ (Davidge et al., 1973).

In the next section, equation (5) describing microcrack growth time-dependent failure is incorporated into a batch of numerical grains with statistical variations in strength. The aim is to discover whether DEM simulations recover an SPT diagram similar to Fig. 6.

\section{DEM simulations}

Agglomerate creation. Soil grains are represented here by agglomerates. Robertson (2000) developed an agglomerate model that allows grain breakage. The agglomerates were created by first bonding individual spheres together into a

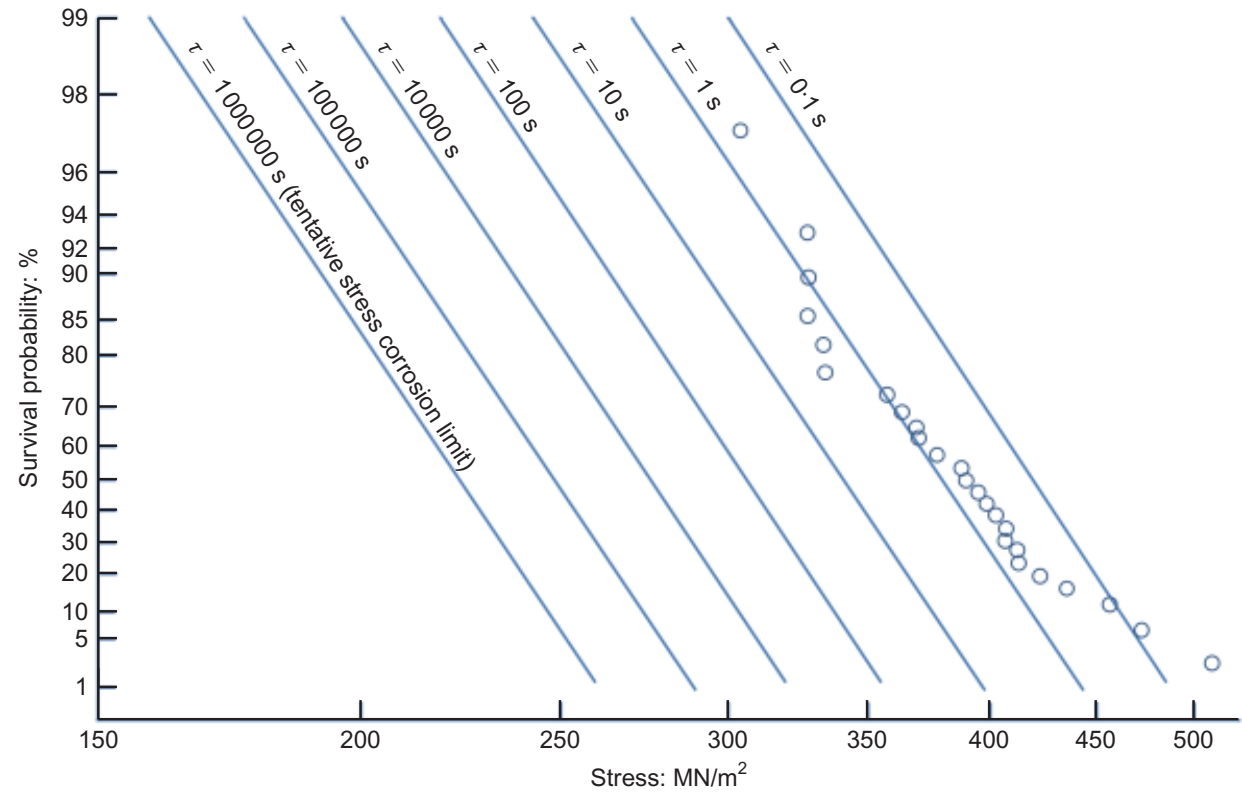

Fig. 6. SPT diagram for $\mathrm{Al}_{2} \mathrm{O}_{3}$; superimposed are the delayed fracture data normalised to a failure time $\tau=1 \mathrm{~s}$ (Davidge et al., 1973) 
regular assembly in hexagonal close packing (HCP). HCP was chosen in order to avoid the overlapping of spheres, and to minimise the space between the spheres. It gives the densest available packing in the spherical volume.

The statistical variation of the strength and shape of agglomerate is provided by giving each elementary sphere a probability of existence of $80 \%$ when it is created. This gives a coordination number around 9.3. The purpose of $20 \%$ ball removal is to create some flaws. Twenty different agglomerates were created, as in Cheng et al. (2003), and they are shown in Fig. 7. The properties of a typical agglomerate are given in Table 1. The sphere size, initial bond strength and percentage removal of spheres were carefully selected by Robertson (2000) such that the characteristic strength and statistical variation (Weibull modulus) match those of silica sand.

Compression. Compression tests were simulated on randomly oriented agglomerates, which were placed between two smooth and stiff platens. A linear contact model and a default local damping ratio of 0.7 were used. The agglomerate was rapidly compressed in the vertical direction to different applied stresses with the use of the stress-control algorithm. The target stress has to be smaller than the shortterm failure stress. The mean strength of the batch of 20 agglomerates was approximately $60 \mathrm{MPa}$. Fig. 8 shows a DEM agglomerate with its contact force chains early in the
Table 1. Properties of a typical agglomerate

\begin{tabular}{l|c}
\hline Input parameter & Value \\
\hline Radius of agglomerate: mm & $0 \cdot 5$ \\
Radius of sphere: $\mathrm{mm}$ & $0 \cdot 1$ \\
Density of sphere: $\mathrm{kg} / \mathrm{m}^{3}$ & 2650 \\
Average number of spheres in agglomerate & 45 \\
Average number of bonds in agglomerate & 146 \\
Normal and shear bond strength: N & 4 \\
Normal and shear stiffness of each sphere: N/m & $4 \times 10^{6}$ \\
Frictional coefficient of sphere & $0 \cdot 5$ \\
Percentage of spheres removed at random & $20 \%$ \\
\hline
\end{tabular}

compression test, and at peak strength. Initially, both compression and tension were distributed uniformly around the agglomerate, as well as the contact bonds. After compression, there were mainly compression force chains within the agglomerate, even though not many bonds were broken at this stage of the compression.

Crack growth. The stress was maintained constant once the required stress was achieved, and equation (5) was incorporated into the DEM simulation with a reference time $t_{0}=1$ time unit, arbitrarily taken as 1 timestep. The bond strength between each sphere in the agglomerate then

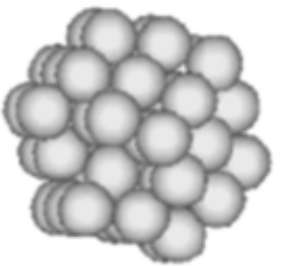

$(49,156)$

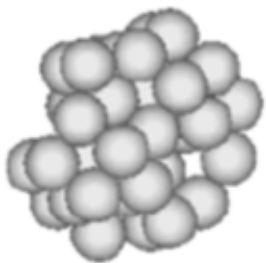

$(41,115)$

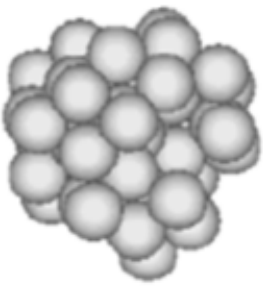

$(45,148)$

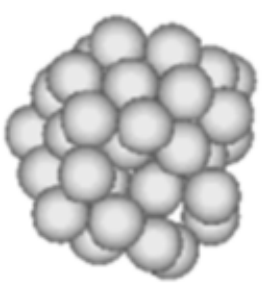

$(45,146)$

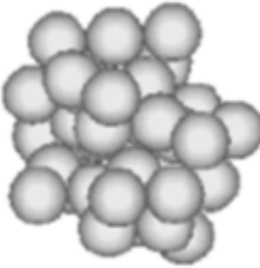

$(36,88)$

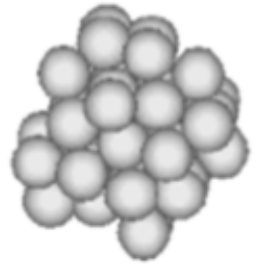

$(43,139)$

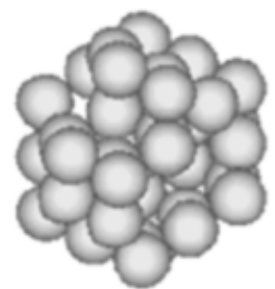

$(44,130)$

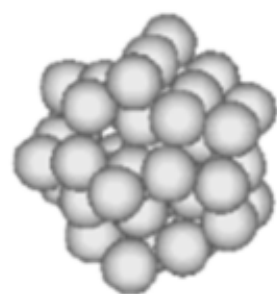

$(44,126)$

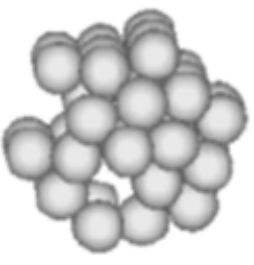

$(44,131)$

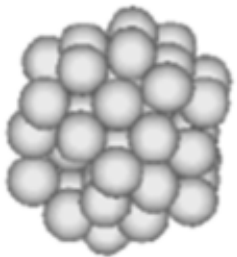

$(46,144)$

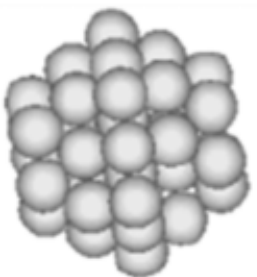

$(46,141)$

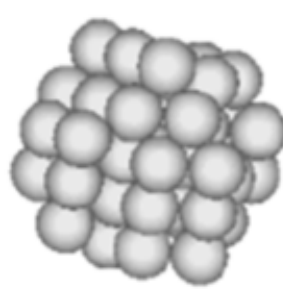

$(50,177)$

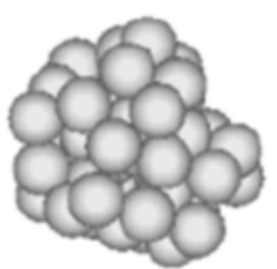

$(46,147)$

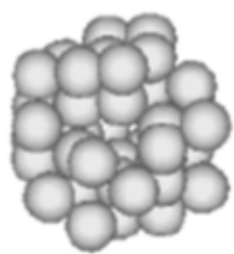

(44, 135)

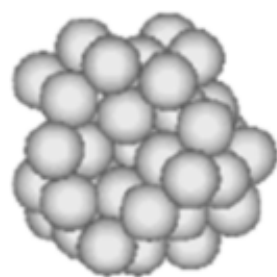

$(44,139)$

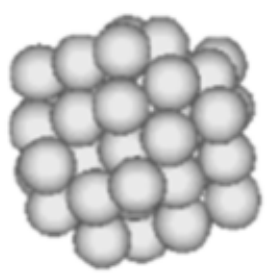

$(45,137)$

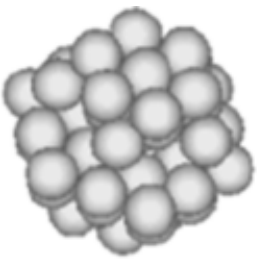

$(49,154)$

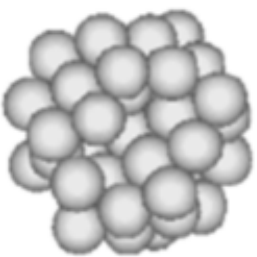

$(46,144)$

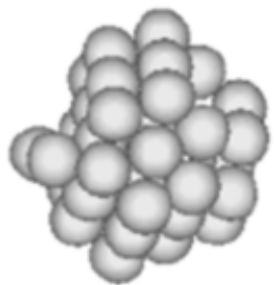

$(44,147)$

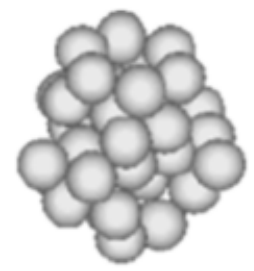

$(42,137)$

Fig. 7. The 20 grains used in the simulations (Cheng et al., 2003). Average number of balls in agglomerate, number of bonds in agglomerate $=45 \cdot 7,246 \cdot 6$ 

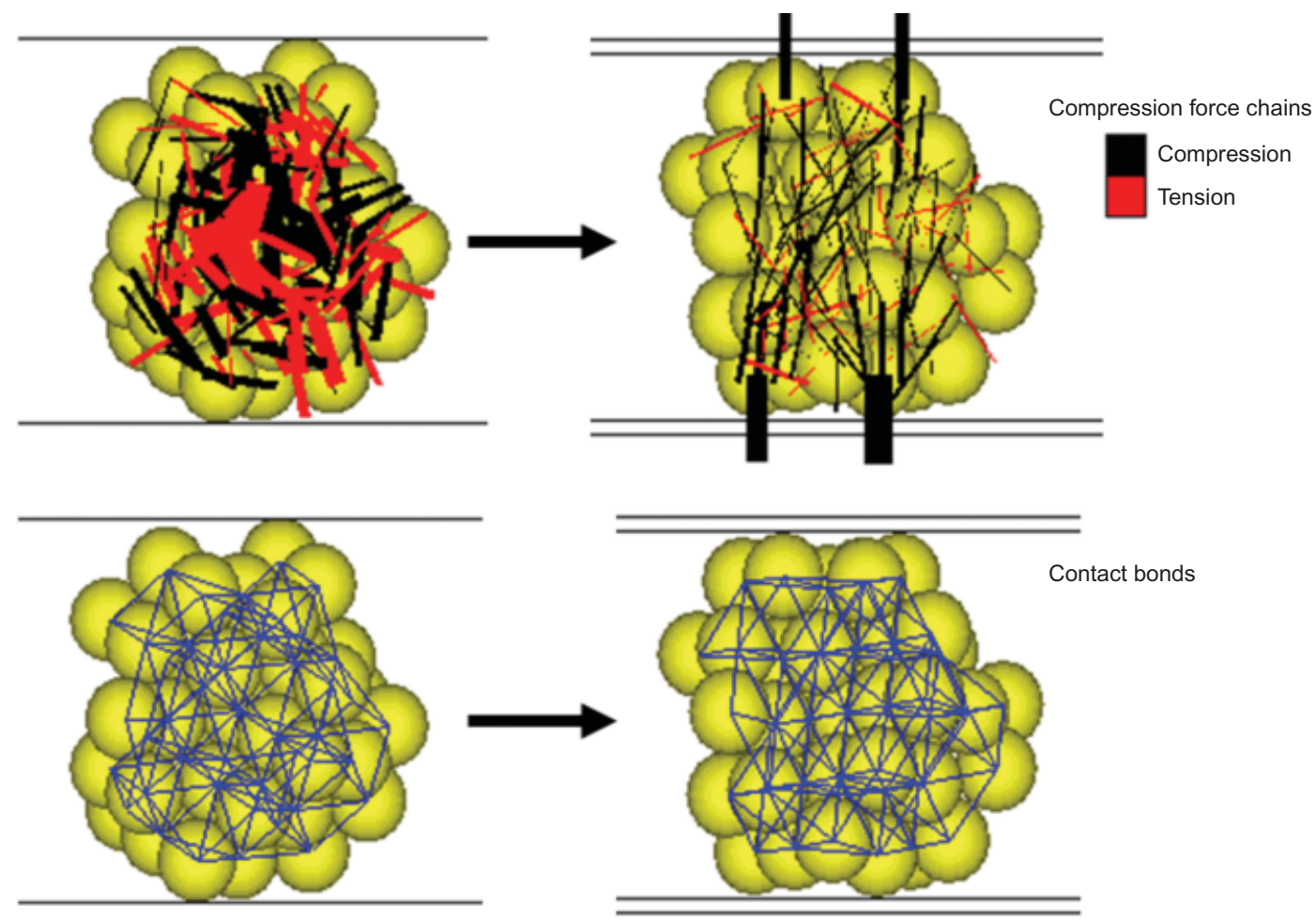

Fig. 8. Schematic diagrams of contact force chains and contact bonds of a specific agglomerate before and after compression simulation

weakens with the allowance of further timesteps, and the agglomerate will eventually break up. The number of timesteps required for each agglomerate to break up is recorded.

Figure 9 shows a DEM agglomerate with its contact force chains before and after the crack growth test. At the end of the test, the agglomerate deformed in a ductile fashion.
There are much fewer contact bonds, and the tensile force chains are now much smaller in magnitude.

Figure 10 shows the number of timesteps required for an agglomerate subjected to different stresses to reach $30 \%$ strain, which was taken arbitrarily as an indication of failure. The predicted logarithm of grain strength decreases in a nearly linear fashion with the logarithm of time, which is in
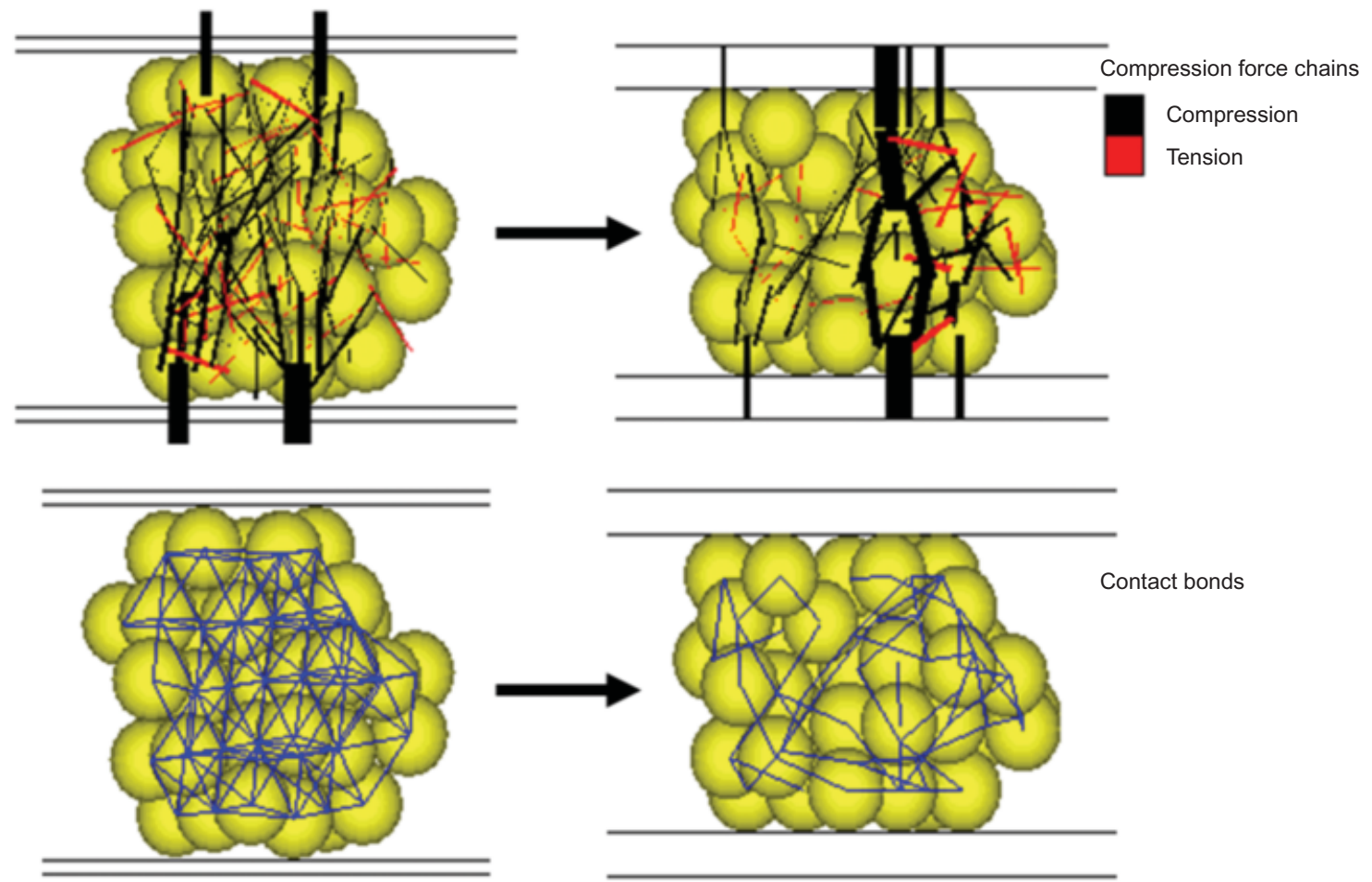

Fig. 9. Schematic diagrams of contact force chains and contact bonds of a specific agglomerate before and after crack growth simulation 


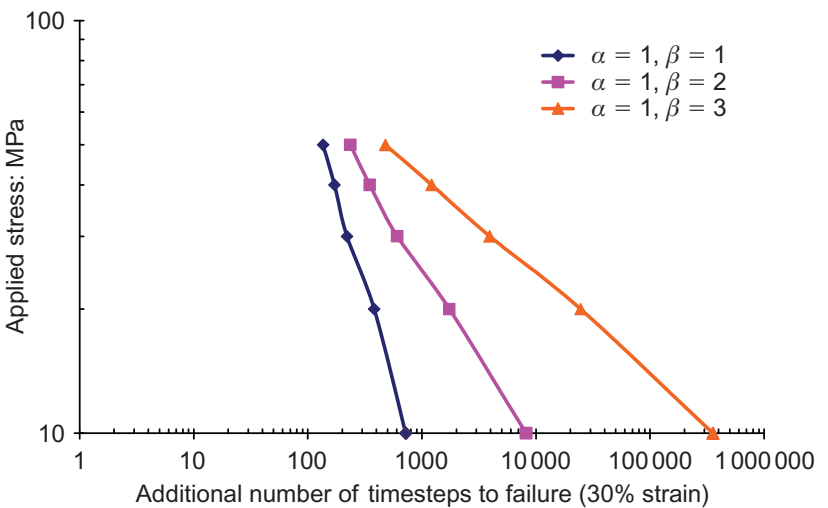

Fig. 10. Time effect of an agglomerate under different stresses at different $\beta$ values

good agreement with results for ceramics obtained by Davidge et al. (1973), according to equation (8). It is observed that all the other agglomerates behave similarly. Agglomerates fail quicker with increasing stress and smaller value of $\beta$.

\section{The SPT diagram}

In order to generate an SPT diagram, a batch of 20 different agglomerates were compressed to $10 \mathrm{MPa}$ for deterioration of grain strength under sustained loading. Results are detailed in Table 2. The parameter $\alpha$ was chosen to be 1 , and different values of $\beta$ were tried in order to obtain the same Weibull modulus $(m=3)$ as for silica sand, which is shown in Fig. 3(b). In Fig. 11, it is found that when $\beta$ equals $2 \cdot 3, m$ is approximately $3 \cdot 4$, which fits closely. The SPT diagram obtained from DEM agglomerates is in good agreement with results for alumina obtained by Davidge et al. (1973), shown in Fig. 6.

The $n$-value can then be estimated using equation (13), which gives about 2.9. An agglomerate was compressed at strain rates of $1 \mathrm{~m} / \mathrm{s}$ and $0 \cdot 1 \mathrm{~m} / \mathrm{s}$. The same peak strength, and no rate effect, was observed without the incorporation of the crack growth equation. However, with the incorporation of the equation, different peak strengths were obtained.

Table 2. Delayed fracture data

\begin{tabular}{l|r|c|r}
\hline $\begin{array}{l}\text { Specimen } \\
\text { number }\end{array}$ & $\begin{array}{c}\text { Failure time* }^{*} \\
\text { (timesteps) }\end{array}$ & $\begin{array}{c}\text { Equivalent stress at 1 } \\
\text { time unit: MPa }\end{array}$ & Rank \\
\hline 1 & 23749 & 323 & 17 \\
2 & 1744 & 131 & 1 \\
3 & 423426 & 872 & 20 \\
4 & 15955 & 281 & 11 \\
5 & 4451 & 181 & 5 \\
6 & 5294 & 192 & 6 \\
7 & 9674 & 237 & 7 \\
8 & 19255 & 300 & 14 \\
9 & 13797 & 268 & 9 \\
10 & 15849 & 281 & 10 \\
11 & 13241 & 264 & 8 \\
12 & 2476 & 148 & 2 \\
13 & 18853 & 298 & 13 \\
14 & 23340 & 321 & 16 \\
15 & 4902 & 187 & 4 \\
16 & 30691 & 353 & 3 \\
17 & 3483 & 166 & 19 \\
18 & 46927 & 408 & 12 \\
19 & 16833 & 287 & 15 \\
20 & 21567 & 312 & \\
\hline & & & \\
\hline
\end{tabular}

* Failure time is defined as time to obtain $30 \%$ strain.

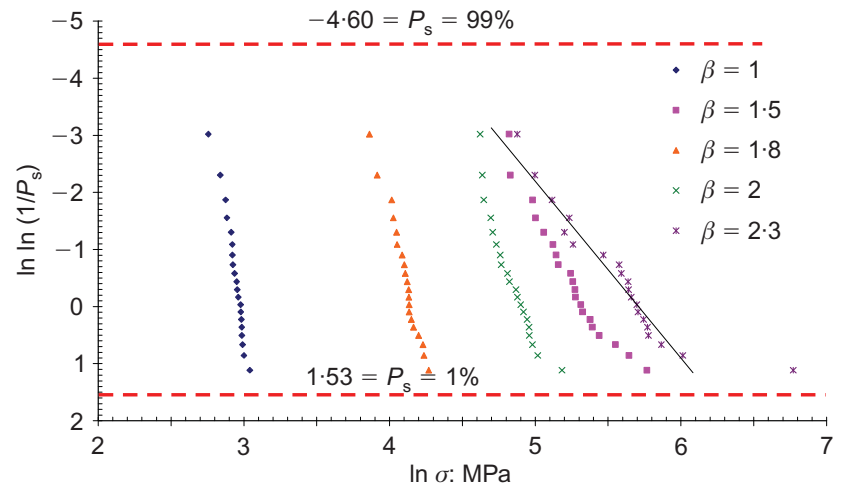

Fig. 11. SPT diagram for 20 agglomerates

The survival probabilities $P_{\mathrm{s}}$ of the 20 agglomerates are calculated for each applied stress using the mean rank position (Davidge, 1979)

$$
P_{\mathrm{s}}=1-\frac{i}{N+1}
$$

in which $i$ is the rank position of a grain when sorted into increasing order of equivalent stress, and $N$ is the number of specimens, which is 20 in this case. Equivalent stresses in Table 2 were calculated according to equation (8) with $n=2 \cdot 9$.

\section{The relationship between $\alpha$ and timestep}

As mentioned earlier, $\alpha$ controls the rate of degradation. Fig. 10 shows that for a decrease of strength with time at a particular rate with $\alpha=1$ and $\beta=3$, it takes about 1000 cycles for strength to drop by $20 \%$ from $50 \mathrm{MPa}$ to $40 \mathrm{MPa}$. With the integration timestep of $1.36 \times 10^{-8} \mathrm{~s}$, the time for this strength decrease to occur is only $1.36 \times 10^{-5} \mathrm{~s}$. The decay of strength is set to happen at such a fast rate because the equivalent timestep would have required billions of integration cycles and years of computer time for the simulation if a realistic rate of strength reduction had been specified.

Taking exponentials on both sides of equation (5) yields

$$
B=B_{0}\left(\frac{t}{t_{0}}\right)^{-\alpha\left(T_{\mathrm{eq}} / B_{0}\right)^{\beta}}
$$

where $N$ is the number of timesteps. For two specimens to yield the same strength reduction $B / B_{0}$ at a given value of $\left(T_{\mathrm{eq}} / B_{0}\right)$, equation (15) requires

$$
N_{1}^{\alpha_{1}}=N_{2}^{\alpha_{2}}
$$

If it took a more realistic period of one day (approximately $10^{5} \mathrm{~s}$ ) for a decrease in strength of $20 \%$ to take place, it would take $10^{13}$ steps to complete the simulation. Referring back to the 1000 cycles required to achieve a $20 \%$ drop in strength with $\alpha=1$

$$
\begin{aligned}
\left(10^{3}\right)^{1} & =\left(10^{13}\right)^{\alpha_{2}} \\
\alpha_{2} & =\frac{3}{13} \approx 0.23
\end{aligned}
$$

The value of $\alpha$ for a decrease of strength by $20 \%$ in 1 day is therefore approximately $0 \cdot 23$. The larger the value of $\alpha$, the higher the rate of degradation in an exponential relationship with timestep.

Unfortunately, it is not practical simply to set $\alpha$ as $0 \cdot 23$, for example, and repeat the DEM simulation. It took only $10 \mathrm{~min}$ to solve for $10^{3}$ steps with $\alpha=1$, but if it took $10^{13}$ steps to solve with $\alpha=0 \cdot 23$, the equivalent computation 
time would be 200000 years. Because the power-law equation (16) has been established relating equivalent times with different $\alpha$-values, it is proposed simply to use this relation to predict the creep times that would have been observed in the 200000 -year computation.

Although the power-law scaling of time is inconsistent with Newton's second law of motion, this is not thought to detract from the validity of these creep prediction. Creep is an extremely slow process, modelled here as a material weakening due to chemical reactions, and negligible mass accelerations are involved.

\section{CREEP IN A TRIAXIAL TEST \\ DEM simulations}

By monitoring the interaction between particles, the behaviour of the material can be explored. The test procedures are as follows.

(a) Create and pack particles in an assembly.

(b) Bring the assembly to an initial isotropic stress state.

(c) Shear the assembly to failure in triaxial test simulation.

(d) Let the assembly creep.

Sample creation. Following Robertson (2000), a cubical sample of dimension of $6.66 \mathrm{~mm}$ was created within six frictionless but very stiff (100 times the stiffness of spheres) walls. At first, 389 'exospheres' of diameter $0.625 \mathrm{~mm}$ were created. These exospheres are used as reference volumes in which bonded elementary spheres arranged in 'crystallographic' arrays are created within the space. The exospheres were then expanded to the desired diameter of $1 \mathrm{~mm}$. The exospheres are assigned a large normal and shear contact stiffness $\left(4 \times 10^{8} \mathrm{~N} / \mathrm{m}\right), 100$ times the original value, and with zero coefficient of friction. This is intended to encourage particle rearrangement so that no significant overlaps of these exospheres would occur. The assembly of exospheres was then cycled to equilibrium with a minimum unbalanced force. The cubical assembly of exospheres is shown in Fig. 12(a). It is closely packed, with a void ratio of about $0 \cdot 5$, which is lower than the minimum void ratio specified for a randomly packed assembly of spheres. This may be either due to some overlapping in the sample prepared in $\mathrm{PFC}^{3 \mathrm{D}}$ of $1 \%$, or because the number of agglomerates is too small to give a truly randomly packed sample.

A linked list storing the coordinates of the centres of the exospheres was created. The exospheres were then deleted. Randomly rotated aggregates made of $0.2 \mathrm{~mm}$ diameter spheres were created in their place. At this point, the variability of strength of the agglomerates is created by removing $20 \%$ of the spheres. Fig. 12 (b) shows the assembly of 378 agglomerates, which comprises 17274 spheres. The density becomes lower at this stage, with a void ratio of about $3 \cdot 1$, because of the internal voids and surface roughness of the agglomerates. In calculating the void ratio, the total volume of the spheres is taken as the solid volume. The contact bond strength was set to a very high value of $1 \times 10^{6} \mathrm{~N}$ in order to prevent bond breakage from occurring during isotropic compression. The assembly was cycled to equilibrium before commencing the test.

Isotropic compression. At this stage, the normal and shear contact stiffnesses of the spheres are set to the final value of $4 \times 10^{6} \mathrm{~N} / \mathrm{m}$, and the coefficient of friction is set to 0.5 . Robertson (2000) tried single-particle-crushing (SPC) tests for different stiffness-bond strength ratios. By comparing the slope of the force-strain graph between the SPC test and

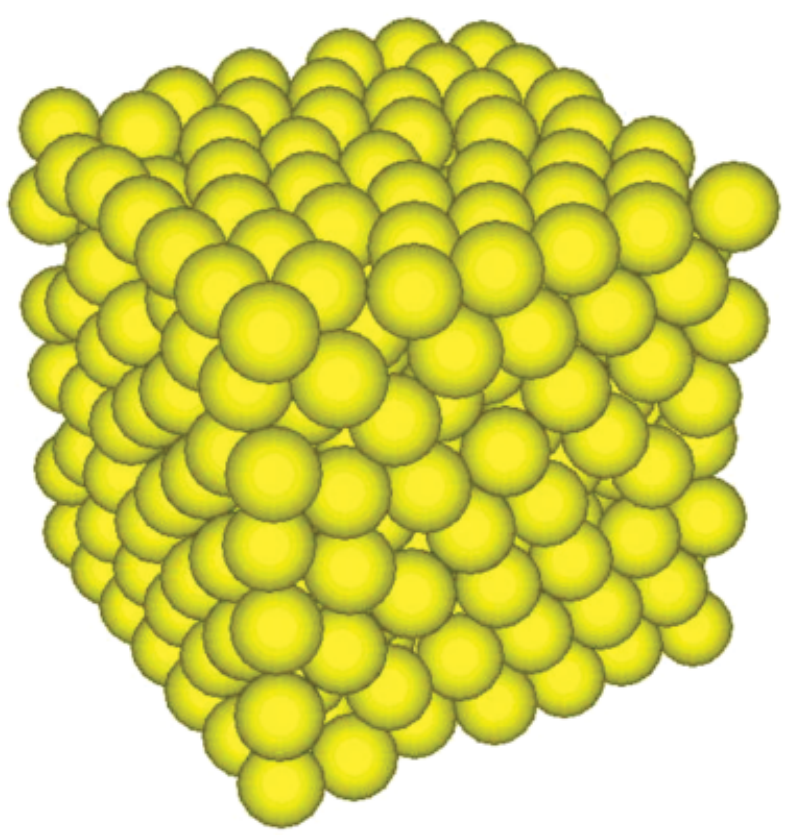

(a)

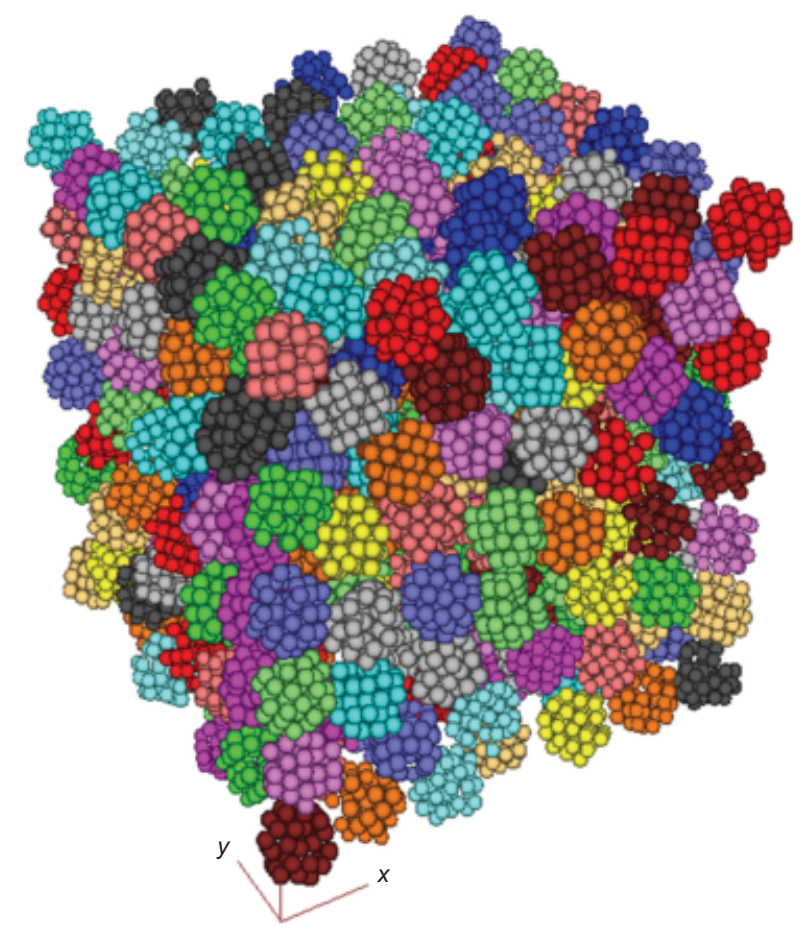

(b)

Fig. 12. Discrete-element modelling cubical assembly of: (a) exospheres; (b) agglomerates

laboratory test from Nakata et al. (1999), it was found that a sphere stiffness of $4 \times 10^{6} \mathrm{~N} / \mathrm{m}$ produces the most appropriate particle stiffness. The cubical assembly of 378 agglomerates was isotropically compressed to $1 \mathrm{MPa}$. The void ratio of the assembly at the end of this stage was about 2 .

Drained triaxial shear test. The assembly was then sheared by moving the top and bottom walls so as to approach each other with a closing speed of $0.2 \mathrm{~m} / \mathrm{s}$ (constant axial strain rate of $30 \% / \mathrm{s}$ ). This speed is slow enough to avoid any inertia effects due to bouncing of initially unloaded agglomerates, but fast enough for a reasonable computational time. Throughout the loading process, the confining stress was 
maintained nearly constant by a stress-control algorithm. The bond strength was reduced to $B_{0}=4 \mathrm{~N}$ at the beginning of the test to allow bond breakage, and this was arbitrarily associated with a duration of $t_{0}=1$ timestep.

Drained creep test. After the assembly had been compressed to a given stress level, it was allowed to creep while the stresses in all directions were maintained constant. This was accomplished by continually adjusting the length, width and height of the assembly with the use of the stress-control mechanism. These adjustments are required because of the small movements that occur between the particles during each timestep. The small changes in stresses that had resulted from the most recent width and height adjustments were used to estimate appropriate adjustments for the next timestep.

\section{DEM RESULTS}

Figure 13 compares the results of triaxial compression tests conducted on the assembly with an axial strain rate of $30 \% / \mathrm{s}$, with and without the crack growth law. The deviator stress $q$ has been normalised with respect to the initial confining pressure $p_{0}$. It appears that there is no difference at the beginning of the two curves. The peak strength ratio $q / p_{0}$ of the assembly without crack growth is about 4 . Softening observed for the assembly with crack growth leads to a lower peak strength ratio of the assembly of about 3.4 .

The stress-strain paths of six creep tests at different stress levels are shown in Fig. 14. The deviator stress $q$ $\left(=\sigma_{\mathrm{a}}-\sigma_{\mathrm{c}}\right)$ in Fig. 14 has been normalised with respect to the maximum deviator stress $q_{\max }$. A soil sample was sheared in triaxial compression to stress-strain states such as $0.3,0.45,0.58,0.68,0.75$ and 0.82 at point A. The creep process is monitored while maintaining the stress constant over time. As strain advances, the strain state moves toward

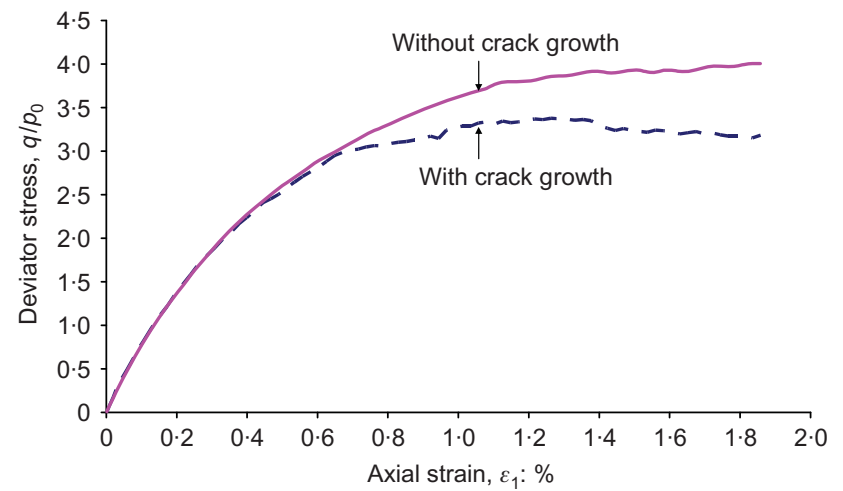

Fig. 13. Stress-strain curves with and without crack growth

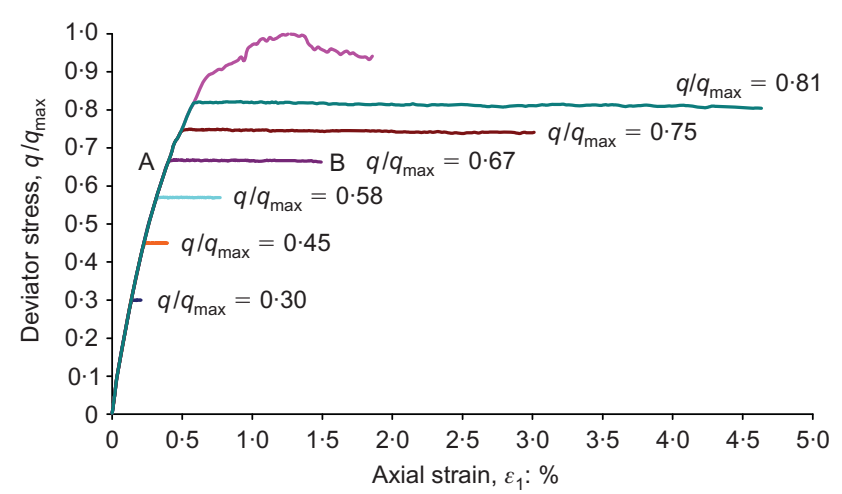

Fig. 14. Deviator stress against axial strain of triaxial compression and creep tests points such as B. All tests were performed under drained conditions, which naturally produced both deviatoric and volumetric deformations.

Figure 15 shows the volumetric strains plotted against axial strain. The volumetric strains from these tests indicated additional compressive behaviour for samples at low stress ratios, but with the samples showing some dilation as creep failure was approached. In each case, there is a roughly constant dilation rate during creep, due jointly to shearing and fragmentation-induced compaction. No unique dilatancy relation is found here. The fragments generated from the particle breakage form a better grading of grains, so that they can fit better together and form a closer packing: hence more compression was induced.

Figure 16 is a plot of $\log$ (axial strain) against $\log$ (time) for six simulations of shear deformation and creep performed at a confining stress of $1 \mathrm{MPa}$. Each creep test was terminated after about $0.0014 \mathrm{~s}$ of simulated creep (equivalent to 2 days of computation time with a Xeon $3.06 \mathrm{GHz}$ computer). The short duration but fast rate of creep test is due to the use of the large value of $\alpha$; the relationship of $\alpha$ with time was discussed earlier. The graph can be stretched to different scales in order to match realistic creep times. At any given time, the magnitudes of the axial strains are generally larger at larger stress levels. Tests with higher deviator stress reached the tertiary creep stage, and seemed to be approaching creep rupture. Creep-induced failure may have occurred when the total axial strain reached about $5 \%$. The creep tests performed at a lower deviator stress might also have eventually reached creep rupture if the tests had continued. This is illustrated with the assumed extensions in Fig. 16.

The axial strain data in Fig. 16 can be differentiated with respect to time to obtain the axial strain rate as a function of time in Fig. 17. The higher lines correspond to tests with a greater applied deviator stress. As the deviator stress

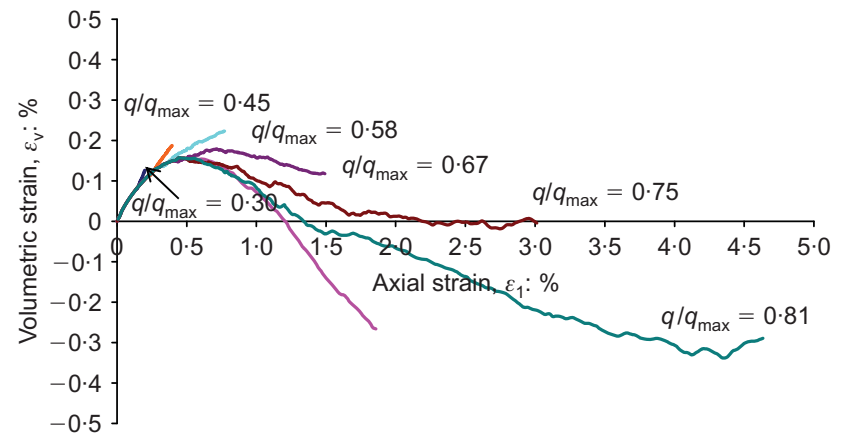

Fig. 15. Volumetric strain against axial strain of triaxial compression and creep tests

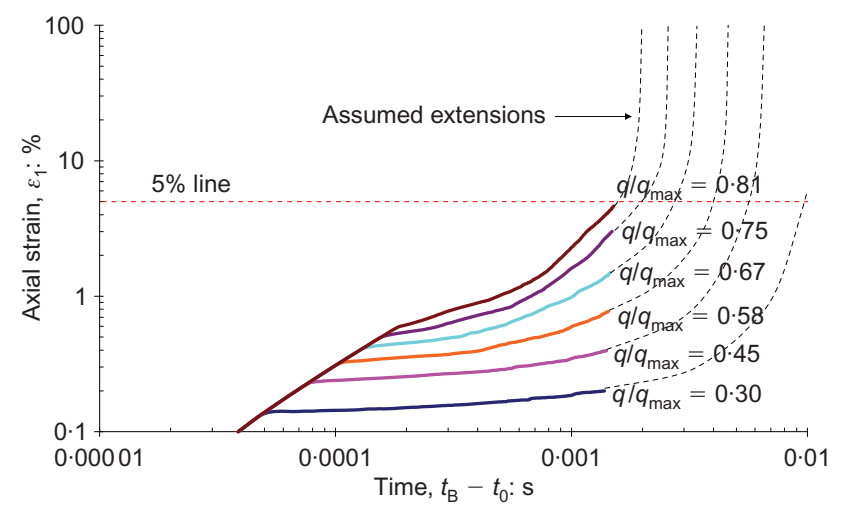

Fig. 16. $\log ($ axial strain) against $\log ($ time) during triaxial compression and creep simulation 


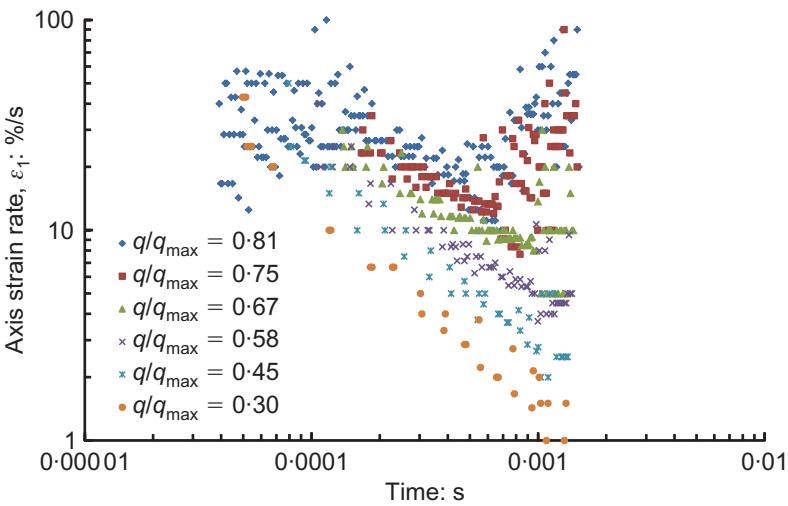

Fig. 17. Log(strain rate) against $\log ($ time) during triaxial compression and creep simulation

approaches the strength of the material, the strain rates become very large, and signal the onset of failure. The relationship between $\log \left(\dot{\varepsilon}_{1}\right)$ and $\log ($ time $)$ is linear, and the three distinct regions of creep behaviour - primary, secondary and tertiary creep - can be roughly displayed.

Figure 18 shows the percentage of bonds broken against creep strain. The amount of bond breakage increases with load. Breakage seems to occur even at low deviator stress. However, breakage at high deviator stress levels can incur more creep strain. Eventually creep must stop, as the sample will run out of bonds to break.

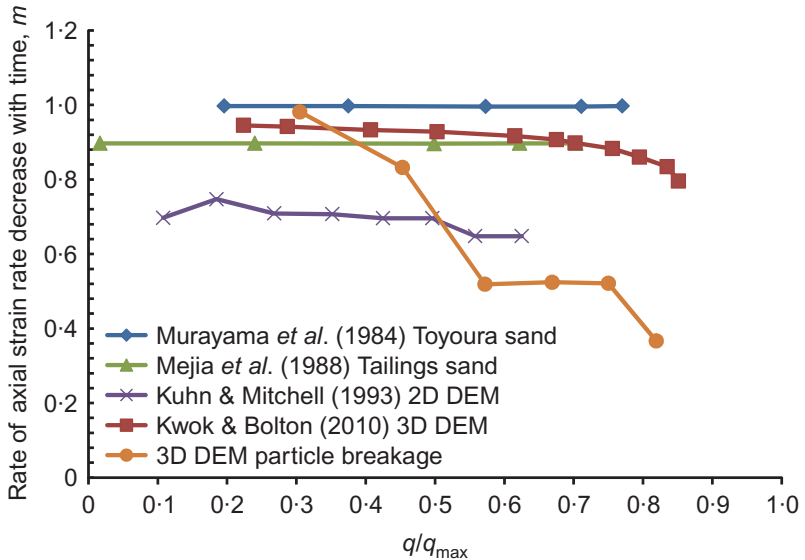

(a)

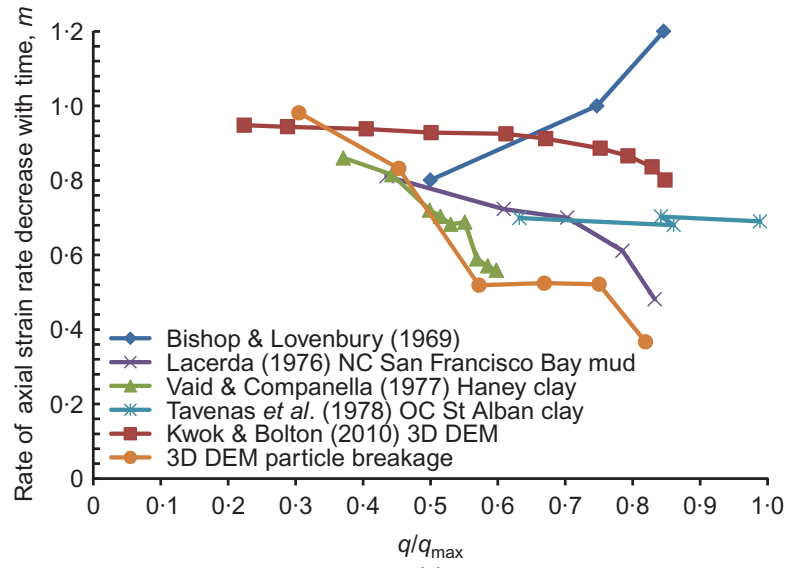

(c)

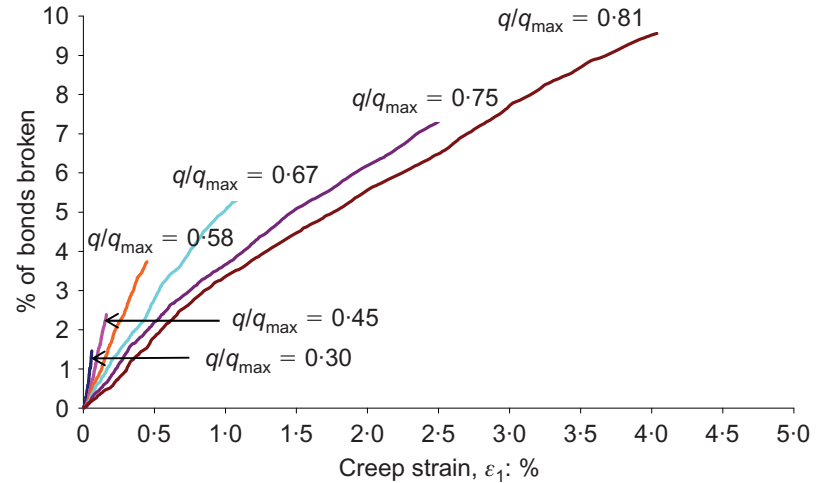

Fig. 18. Bond breakages during creep

\section{DISCUSSION}

Figure 19 compares both the power-law creep gradient $m$ and the magnitude of strain rate after $t=10 \mathrm{~min}$ from the triaxial test data of real soils with values obtained from DEM simulations. The two-dimensional (2D) simulations of discs carried out by Kuhn (1987), the PFC3D simulations of the previous study of creep by particle sliding (Kwok \& Bolton, 2010) and the present study of particle breakage are compared in Figs 19(a) and 19(b) against sands, and in Figs 19(c) and 19(d) against clays.

For smaller deviatoric mobilisations $\left(q / q_{\max }<0.5\right)$, the $m$ parameter of real sands in Fig. 19(a) appears to be in the

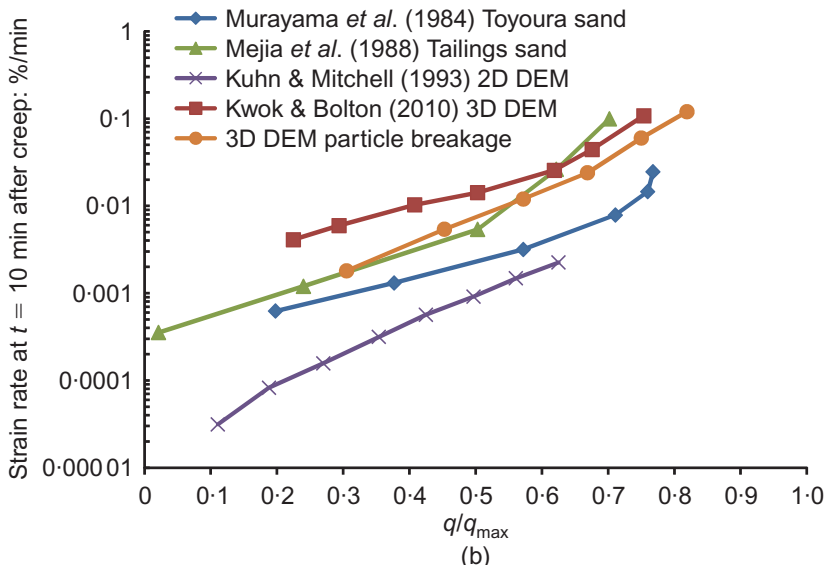

(b)

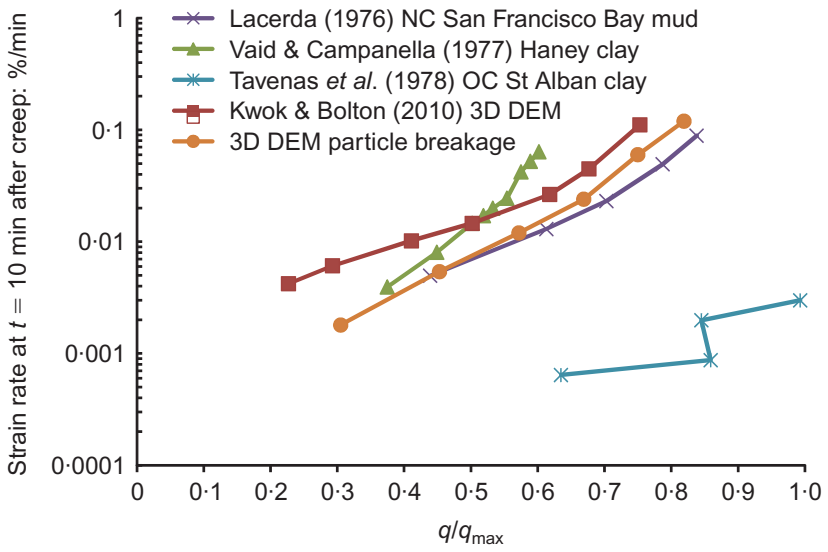

(d)

Fig. 19. Comparisons of: (a) rate of reduction of $\log ($ strain rate) with $\log ($ time) at different deviator stress levels for sands; (b) strain rate after $t=10 \mathrm{~min}$ of creep at different deviator stress levels for sands; (c) rate of reduction of $\log (\mathrm{strain}$ rate) with $\log (\mathrm{time})$ at different deviator stress levels for clays; (d) strain rate after $t=\mathbf{1 0} \mathbf{m i n}$ of creep at different deviator stress levels for clays 
range -0.9 to $-1 \cdot 0$, as is the $m$ parameter from $\mathrm{PFC} 3 \mathrm{D}$ reported here. The value of $m$ reported for real sands does apparently reduce at increased deviatoric stresses, but that generated by the current DEM simulations decreases much faster.

In the range of smaller deviatoric mobilisation, the magnitude of the $m$ parameter of real clays in Fig. 19(c) is a little lower than that of real sands in Fig. 19(a). However, it is noticeable that some real clays show a strong reduction in $m$ at higher deviatoric mobilisations $\left(q / q_{\max }>0.5\right)$, which matches closely with the PFC3D results reported here.

In terms of the magnitude of creep strains, it is the strain rate 10 min after the start of creep, given in Figs 19(b) and 19(d), that gives the best indication of creep strain. The amount of creep in sand has been observed to increase at high deviatoric mobilisations in Figs 19(b) and 19(d), and the results match well with the real test data.

Considering both the general trends shown by real sands and clays, and the variability between them, the DEM simulations of creep shown here appear to fit reasonably well. Considering the current difficulty that engineers face in allowing for the effects of soil creep in three-dimensional stress-strain conditions, DEM simulations using the bonding deterioration model set out here, and comparing with the earlier thermally activated creep model (Kwok \& Bolton, 2010), offer a promising way forward for data analysis and prediction.

\section{CONCLUSIONS}

The statistical variation in the strength of grains was modelled successfully with the use of numerical agglomerates, developed by Robertson (2000), which have a Weibull modulus of approximately $3 \cdot 4$, similar to that of silica sand. A time-dependent failure criterion was developed in equation (4) that describes the crack growth corresponding to increasing stress. Statistical effects were combined with the subcritical crack growth time-dependent failure analysis to create an SPT diagram that describes the Weibull strength/ probability-of-survival path corresponding to increasing failure times. The notion of an SPT diagram was devised by Davidge et al. (1973) to predict the failure of ceramic testpieces. In this current work it has first been used to predict the fracture of a single soil grain. The DEM technique was then applied to the simulation of creep in a triaxial test with 378 agglomerates. Below are the main points noted from the simulations.

(a) Crack growth leads to softening of soils and extra compressive strains as fragments generated from the particle breakage form a better grading of grains so that they can fit better together and form a closer packing.

(b) Creep strain and creep rate increase with greater applied stress.

(c) Creep-induced failure was expected to occur when the axial strain reaches about $5 \%$.

(d) The DEM results show that the crack growth model can comprehensively produce macroscopic behaviour that is similar to that of soils.

(e) Creep simulations with the crack growth contact model can produce primary creep results similar to those of soils, with the logarithm of strain rate decreasing nearly linearly with the logarithm of time.

\section{ACKNOWLEDGEMENT}

The authors would like to acknowledge the assistance of Dr Helen Cheng for giving permission to use the electronic files of her bonded agglomerates in this paper.

\section{NOTATION}

$A \quad$ wall area

$B$ bond strength

$B_{0}$ initial bond strength

$E$ elastic modulus

$i$ rank position of a grain

$k$ Weibull failure-time distribution failure rate

$m$ rate of reduction in $\log$ (strain rate) with $\log$ (time)

$m$ Weibull modulus

$N$ number of specimens

$n$ slow crack growth exponent

$P_{\mathrm{s}} \quad$ probability of survival

$p_{0} \quad$ initial mean stress

$p_{0}$ initial confining pressure

$q$ deviator stress, $\sigma_{\mathrm{a}}-\sigma_{\mathrm{c}}$

$q_{\max }$ maximum deviator stress

$S$ shear force

$S_{\mathrm{f}}$ shear force at failure

$T$ tensile force

$T_{\mathrm{eq}}$ equivalent tensile force

$T_{\mathrm{f}}$ tensile force at failure

$t$ time

$t_{\mathrm{B}}$ time after the start of creep

$t_{0}$ initial time

$t_{1}, t_{2}$ arbitrary reference times

$V$ volume

$V_{0} \quad$ characteristic volume

$\alpha$ a parameter that controls the rate of degradation

$\beta$ a parameter that influences the sensitivity of the rate of deterioration to the current tensile force

$\varepsilon_{1} \quad$ axial strain

$\varepsilon_{2} \quad$ axial strain at point 2

$\varepsilon_{\mathrm{v}} \quad$ volumetric strain

$\dot{\varepsilon}$ strain rate

$\dot{\varepsilon}_{0} \quad$ initial axial strain rate

$\dot{\varepsilon}_{1} \quad$ axial strain rate

$\dot{\varepsilon}_{2}$ axial strain rate

$\sigma \quad$ stress

$\sigma_{0} \quad$ characteristic stress

$\sigma_{1} \quad$ stress at point 1

$\sigma_{2} \quad$ stress at point 2

$\sigma_{\mathrm{a}} \quad$ axial stress

$\sigma_{\mathrm{c}} \quad$ confining stress

$\tau$ shear stress

\section{REFERENCES}

Ashby, M. F. \& Jones, D. R. H. (1998). Engineering materials 2: An introduction to microstructures, processing and design, 2nd edn. Oxford, UK: Butterworth-Heinemann.

Barksdale, R. D. \& Blight, G. E. (1997). Compressibility and settlement of residual soils. In Mechanics of residual soils (ed. G. E. Blight), pp. 95-154. Rotterdam, the Netherlands: Balkema.

Bishop, A. W. \& Lovenbury, H. T. (1969). Creep characteristics of two undisturbed clays. Proceedings of the 7 th international conference of soil mechanics and foundation engineering, Mexico, vol. 1, pp. 29-37.

Cheng, Y. P., Nakata, Y. \& Bolton, M. D. (2003). Discrete element simulation of crushable soil. Géotechnique 53, No. 7, 633-641, http://dx.doi.org/10.1680/geot.2003.53.7.633.

Davidge, R. W. (1979). Mechanical behaviour of ceramics. Cambridge, UK: Cambridge University Press.

Davidge, R. W., McLaren, J. R. \& Tappin, G. (1973). Strengthprobability-time (SPT) relationships in ceramics. J. Mater. Sci. 8, No. $12,1699-1705$

Freiman, S. (1984). Effects of chemical environments on slow crack growth in glasses and ceramics. J. Geophys. Res. 89, No. B6, $4072-4077$.

Hoek, E. \& Brown, E. T. (1980). Empirical strength criterion for rock masses. J. Geotech. Engng Div., ASCE 106, No. GT9, $1013-1035$.

Itasca (2008). PFC3D - Particle flow code in 3 dimensions, ver. 4.0, user's manuals. Minneapolis, MN, USA: Itasca Consulting Group, Inc. 
Karimpour, H. \& Lade, P. (2010). Time effects relate to crushing in sand. J. Geotech. Geoenviron. Engng 136, No. 9, 1209-1219.

Kuhn, M. R. (1987). Micromechanical aspects of soil creep. PhD thesis, University of California, Berkeley, CA, USA.

Kuhn, M. R. \& Mitchell, J. K. (1993). New perspectives on soil creep. ASCE J. Geotech. Engng 119, No. 3, 507-524.

Kwok, C. Y. \& Bolton, M. D. (2010). DEM simulations of thermally activated creep in soils. Géotechnique 60, No. 6, 425-433, http://dx.doi.org/10.1680/geot.2010.60.6.425.

Lacerda, W. A. (1976). Stress-relaxation and creep effects on soil deformation. PhD thesis, University of California, Berkeley, CA, USA.

Lee, K. L. \& Farhoomand, I. (1967). Compressibility and crushing of granular soils in anisotropic triaxial compression. Can. $\mathrm{Geo}-$ tech. J. 4, No. 1, 68-86.

Leung, C. F., Lee, F. H. \& Yet, N. S. (1996). The role of particle breakage in pile creep in sand. Can. Geotech. J. 33, No. 6, 888-898.

McDowell, G. R. \& Amon, A. (2000). The application of Weibull statistics to the fracture of soil particles. Soils Found. 40, No. 5, $133-141$.

McDowell, G. R. \& Bolton, M. D. (1998). On the micromechanics of crushable aggregates. Géotechnique 48, No. 5, 667-679, http://dx.doi.org/10.1680/geot.1998.48.5.667.

McDowell, G. R. \& Khan, J. J. (2003). Creep of granular materials. Granular Matter 5, No. 3, 115-120.

Mejia, C. A., Vaid, Y. P. \& Negussy, D. (1988). Time dependent behaviour of sand. In International conference on rheology and soil mechanics (ed. M. J. Keedwell), pp. 312-326. London, UK: Elsevier.

Mukai, M., Takino, Y. \& Yamazaki, H. (1999). Long term assessment of super-high naming with decomposed granite soil. Proceedings of 54th annual conference of JSCE, 3-(A), pp. 780-781. Hiroshima, Japan: Japan Society of Civil Engineers (in Japanese).

Murayama, S., Michihiro, K. \& Sakagami, T. (1984). Creep characteristics of sands. Soils Found. 24, No. 2, 1-15.
Nakata, Y., Hyde, A. F. L., Hyodo, M. \& Murata, H. (1999). Probabilistic approach to sand particle crushing in the triaxial test. Géotechnique 49, No. 5, 567-583, http://dx.doi.org/ 10.1680/geot.1999.49.5.567.

Oldecop, L. A. \& Alonso, E. E. (2007). Theoretical investigation of the time-dependent behaviour of rockfill. Géotechnique 57, No. 3, 289-301, http://dx.doi.org/10.1680/geot.2007.57.3.289.

Robertson, D. (2000). Computer simulations of crushable aggregates. PhD thesis, University of Cambridge, Cambridge, UK.

Robertson, D. \& Bolton, M.D. (2001). DEM simulations of crushable grains and soils. Proceedings of the 4th international conference on micromechanics of powders and grains, Sendai, Japan, pp. 623-626.

Takei, M., Yoneima, T., Galer, M. M. \& Kusakabe, O. (1998). Time dependent behavior of geomaterials due to particle crushing, Technical Report No. 55, pp. 37-56. Tokyo, Japan: Department of Civil Engineering, Tokyo Institute of Technology.

Takei, M., Kusakabe, O. \& Hayashi, T. (2001). Time-dependent behavior of crushable materials in one-dimensional compression tests. Soils Found. 41, No. 1, 97-121.

Tavenas, F., Leroueil, S., La Rochelle, P. \& Roy, M. (1978). Creep behaviour of an undisturbed lightly overconsolidated clay. Can. Geotech. J. 15, No. 3, 402-423.

Weibull, W. (1951). A statistical distribution function of wide applicability. ASME J. Appl. Mech. 18, No. 3, 293-297.

Wiederhorn, S., Fuller, E. \& Thomson, T. (1980). Micromechanics of crack growth in ceramics and glasses in corrosive environments. Metal Sci. 14, No. 8-9, 450-458.

Vaid, Y. P. \& Campanella, R. G. (1977). Time-dependent behaviour of undisturbed clay. ASCE J. Geotech. Engng 103, No. 7, 693-709.

Vesić, A. S. \& Clough, G. W. (1968). Behaviour of granular materials under high stresses. J. Soil Mech. Found. Div. ASCE 94, No. SM3, 661-688.

Yet, N. S., Leung, C. F. \& Lee, F. H. (1996). Post-installation behavior of pile. Proceedings of the 12th Southeast Asian geotechnical conference, Kuala Lumpur, Malaysia, vol. 1, pp. 429-434. 